\title{
Simulation Research on Brushless DC Motor of Electric Car
}

\author{
Hanpin $\mathrm{Luo}^{\mathrm{a}}$, Jianbo $\mathrm{Cao}^{\mathrm{b} *}$, Zhongyao $\mathrm{Wu}^{\mathrm{c}}$, Chuhang Yang ${ }^{\mathrm{c}}$, Yangyang \\ Zheng $^{\mathrm{C}}$ and Tianfeng Zhao ${ }^{\mathrm{C}}$
}

College of Engineering, Zhejiang Normal University, Jinhua, Zhejiang 321004, P. R. China

azjnulhp@zjnu.cn, ${ }^{\text {b*Corresponding author: caojianbo2008@163.com, }{ }^{\mathrm{C}} 1553541784 @ q q . c o m}$

\author{
Keywords: Electric car, Brushless DC motor, Control, MATLAB
}

\begin{abstract}
Environmental protection and energy issues have already become the two most prominent themes in the new century. Electric car becomes one of the ways to solve these two problems. Aiming at working out how to apply the brushless DC motor to the electric car, a control system was designed after a series of related researches. With the basic principles and methods of operating the brushless DC motor being studied, the simulation model of controlling the brushless DC motor was designed by MATLAB software, and the related parameters were analyzed and studied. The results showed that the brushless DC motor had good controllability, which made it suitable for the application to the electric car.
\end{abstract}

\section{Introduction}

Environmental protection and energy issue have already become the two most prominent themes in the new century. As a new green traffic tool, electric car was invented to solve the social problems such as environmental pollution and energy crisis. It was an important symbol of social development and scientific progress. Since the early 80's last century, that the rapid development of technologies such as the power electronics, micro-electronics, cybernation and the motor provided good conditions for the development of electric car. Scientific-research institutions and vehicle companies in developed countries, represented by Europe, America and Japan, invested a huge sum of money to develop the electric car with the support of governments. And they successfully launched a group of well-performed concept cars .At the same time, as a green traffic tool, electric car will bring great changes to the human society in the 21st century [1-3].

The key component of electric car is electric motor. In order to equip the electric car with better performance, the driving motor should have a wide speed range, a high speed and a starting torque large enough. In addition, as the driving motor is performed in the vehicle running form, the motors used is required to have small volume, light weight, high efficiency and good energy feedback performance [4]. As for the performance requirements of electric car, brushless DC motor not only has the characteristics of the DC motor, but also has the advantages of AC motor. It has good dynamic behaviour and excellent performance of speed governing like the DC motor while with a simple structure, it can be operated soundly and be maintained conveniently like the AC motor. Besides, its electromagnetic torque is large while its pulse is tiny. As for the demand of structure, this kind of motor has short axial dimensions, large core diameter. The type of its structure is flat which makes it convenient to be installed in the bike's back axle. In this way, the torque can be directly added to the rear wheel of the bike when the motor is working, and the bike can be ridden like any other common bicycle when the motor stops working. As a result, brushless DC motor's application in the area of electric car has been in the trend of rising in recent years [5]. This paper will search in the model and simulation of the brushless DC motor.

\section{Control Principle of Brushless DC Motor}

Compared with the rotor of the traditional motor, that of the brushless DC motor chooses the permanent-magnet steel which is made of permanent-magnet materials. Since it is just the opposite to the structure of the traditional permanent-magnet DC motor, it is also called the permanent-magnet 
brushless DC motor (BLDCM). Compared to the traditional brushless DC motor, BLDCM uses the electronic commutation to replace the mechanical commutation used by the original DC motor. Moreover, it reverses the stator rotor of the original brushless DC motor (the rotor uses the permanent-magnet steel) so that the mechanical communication apparatus and electric brush are no more needed [6-7].

Brushless DC motor is made up of motor noumenon, rotor-position-detection circuit and electronic-switch circuit, as shown in Fig.1. Principle drawing of the two phase conduction star six is shown in Fig. 2. The state of the rotor running is shown in Fig. 3. Stator-resultant-magnetic field still spins in the form of great leaps with a step for 60 degrees, namely 1/6 cycle. Each time it turns 60 degrees, the inverter switch tube converters once through six states. Each power tube (each phase winding) conducting 120 degrees. The order is V1V6, V1V2, V2V3, V3V4, V4V5, V5V6. Do as the order can make the motor rotor realize clockwise rotation. If the tubes converter as the order down, the motor can realize inversion.

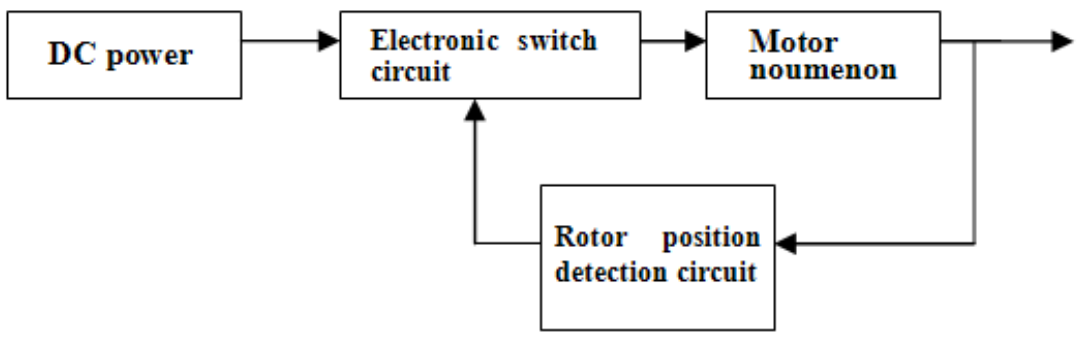

Fig. 1 Brushless DC motor component diagram

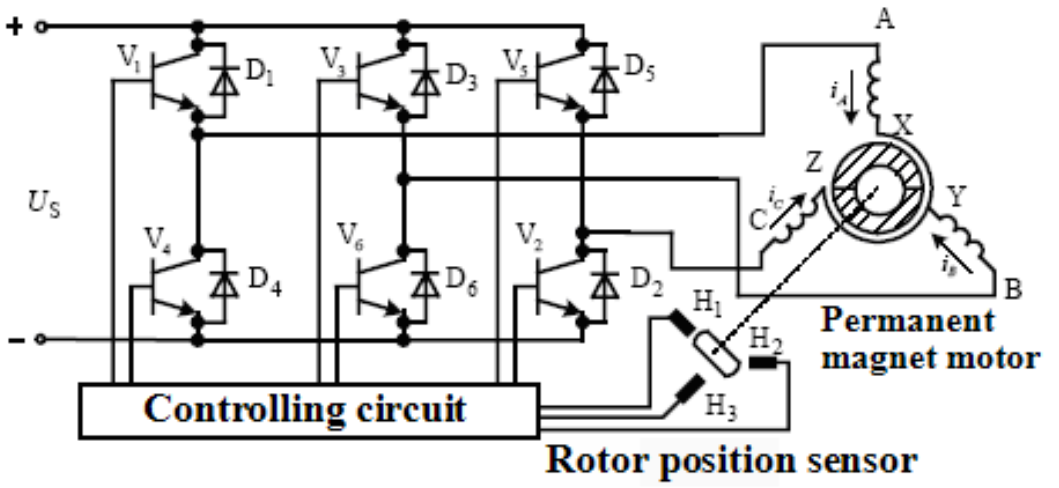

Fig. 2 The principle diagram of two-phase-conduction-star-six state

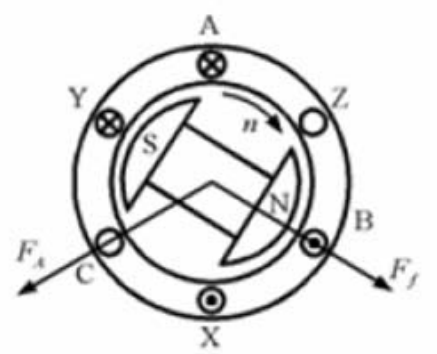

V1V6 conduction

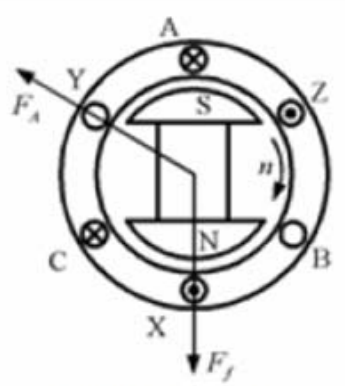

V1V2 conduction

Fig. 3 The state of motor rotor running

According to the Electrical Motor, stator three phase winding's voltage equation can be expressed as:

$$
\left[\begin{array}{l}
u_{a} \\
u_{b} \\
u_{c}
\end{array}\right]=\left[\begin{array}{ccc}
R_{a} & 0 & 0 \\
0 & R_{b} & 0 \\
0 & 0 & R_{c}
\end{array}\right]\left[\begin{array}{l}
i_{a} \\
i_{b} \\
i_{c}
\end{array}\right]+p\left[\begin{array}{ccc}
L_{a} & L_{a b} & L_{a c} \\
L_{b a} & L_{b} & L_{b c} \\
L_{c a} & L_{c b} & L_{c}
\end{array}\right]\left[\begin{array}{l}
i_{a} \\
i_{b} \\
i_{c}
\end{array}\right]+\left[\begin{array}{l}
e_{a} \\
e_{b} \\
e_{c}
\end{array}\right]+u_{n}\left[\begin{array}{l}
1 \\
1 \\
1
\end{array}\right]
$$

where $u_{a} 、 u_{b}, u_{c}$ - motor three phase voltage; $e_{a}, e_{b}, e_{c}-$ motor three instead potential, $i_{a} 、 i_{b} 、 i_{c}-$ motor three-phase current, $R_{a} 、 R_{b} 、 R_{c}$ - three phase winding resistance, $L_{a} 、 L_{b} 、 L_{c}-$ 
three phase winding self-induction, $\mathrm{L}_{\mathrm{ab}}-\mathrm{A}$ and $\mathrm{B}$ phase winding of mutual inductance (others can be inferenced), $u_{n}$ - the neutral point voltage, $p$ - differential operator, $p=\frac{d}{d t}$.

\section{Simulation Research}

Based on the analysis of the mathematical model of brushless DC motor, SIMULINK, which was provided by the MATLAB as a simulation platform, established the model of three-phase-six-state permanent-magnet brushless DC motor. Firstly, in MATLAB/SIMULINK, the independent functional modules were established, such as BLDCM ontology module, rotor position calculation module, commutation logic module and so on, and then the function modules were organically integrated, and the simulation model of the brushless DC motor system was built. The results of the simulation are shown in Fig. 4 to Fig. 7.

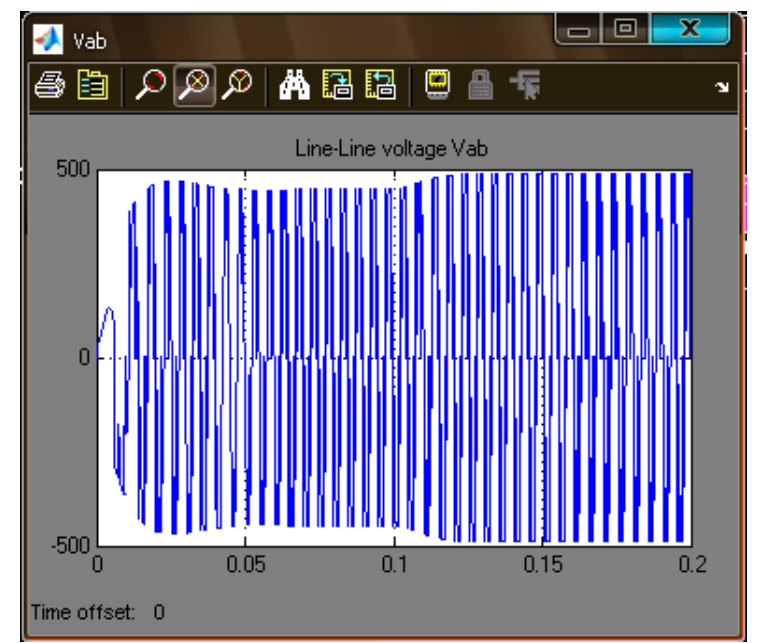

Fig. 4 Brushless DC motor line voltage signal

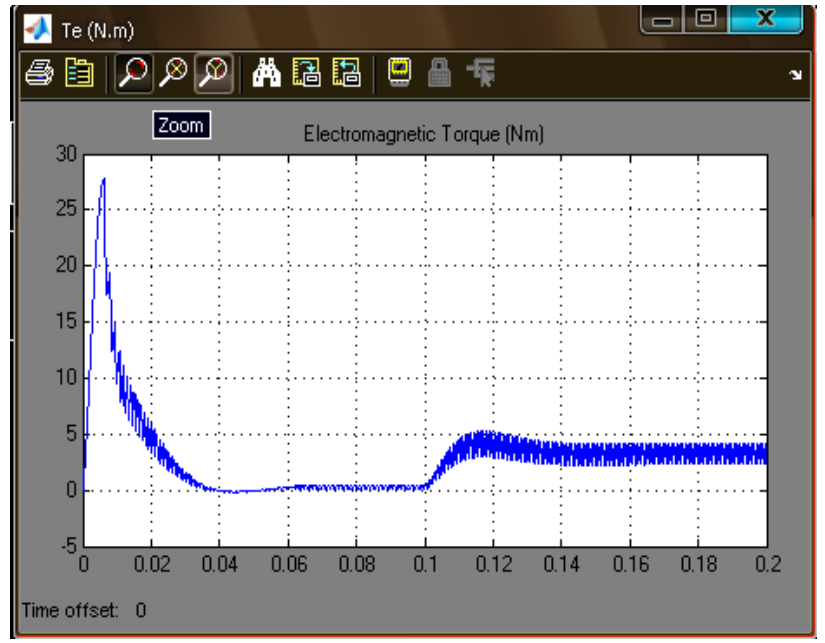

Fig. 5 Torque response curve

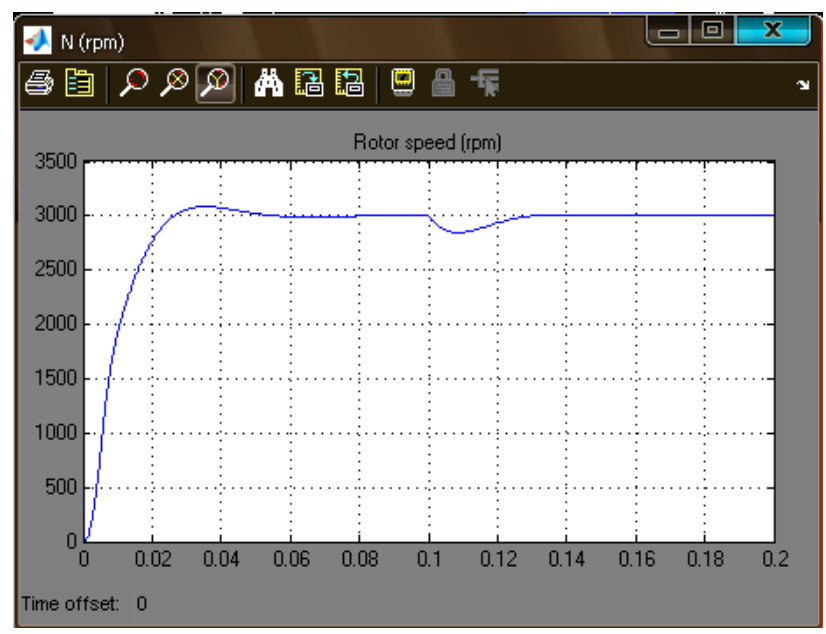

Fig. 6 Speed response curve 


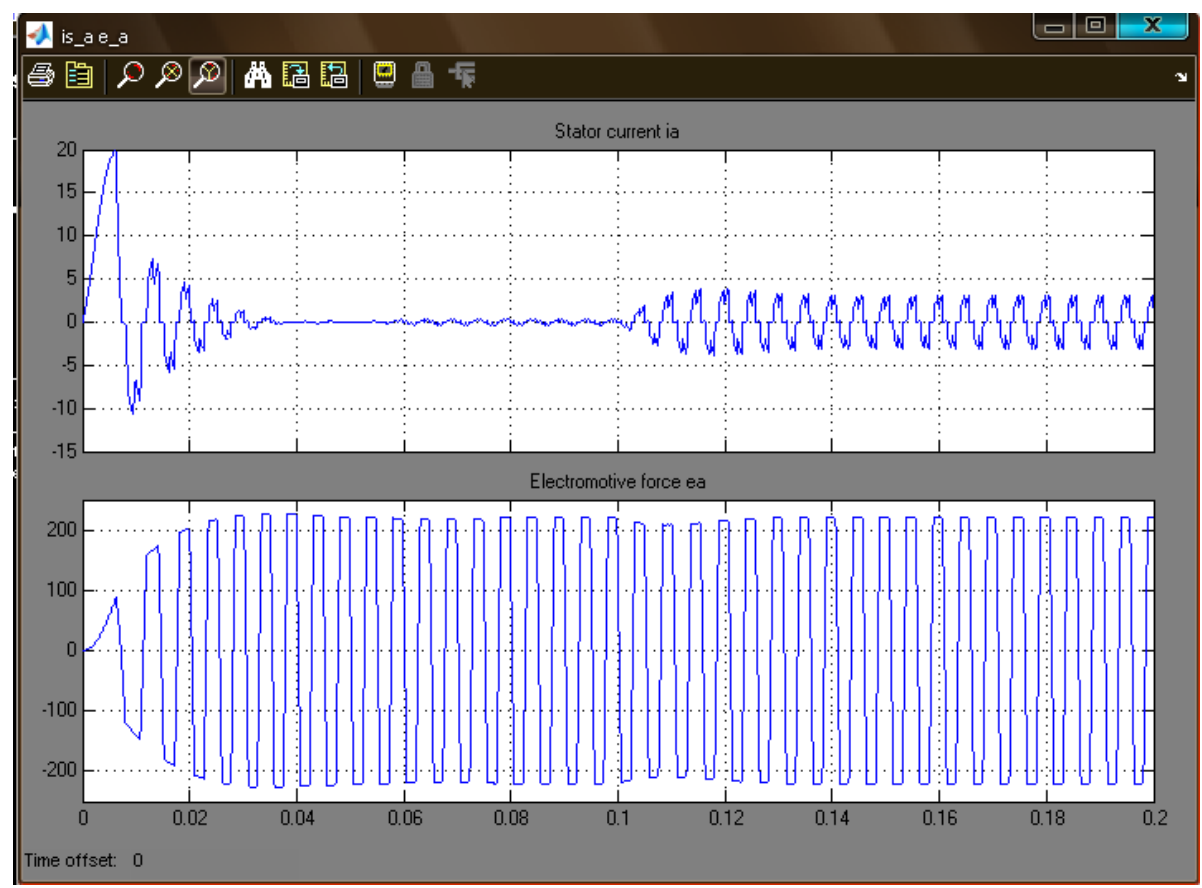

Fig. 7 Induced current and induction electromotive force

\section{Conclusion}

As the science and technology are developing day by day and the ideas of energy conservation are being more and more popular in the society, electric car will take a greater part in people's daily life. This paper analyzes the principle of how to control the brushless DC motor used in the electric car. By using the SIMULINK simulation platform in the MATLAB, the brushless DC motor was modeled and simulated, which would help the further popularization and application of the brushless DC motor.

\section{Acknowledgement}

The work was Supported by the Key Project of Chinese Ministry of Education (No. 211071), the Science and Technology Project of Jinhua City (No. 2010-1-101), and the Key Research Project of Education Department of Zhejiang Province (No. Z201018813).

\section{References}

[1] S.Y. Tang: Motor Technology, (1996), No. 2, pp. 49-51.

[2] Q.F. Zhang, B.Q. Kou and S.K. Cheng: Micro \& Special Motor, (2004) No. 6, pp. 33-37.

[3] T.D. Batzel and K.Y. Lee: IEEE Trans. on Energy Conversion, Vol. 20 (2005) No. 4, pp. 818-825.

[4] J. Pan: Foreign Electronic Components, (2003), pp. 32-34.

[5] J. Zheng and X.P. Wang: Micro \& Special Motor, Vol. 15 (2002) No. 7, pp. 12-23.

[6] R. Ren: Journal of Zhejiang Normal University (Social Sciences), (1991) No. 4, pp. 73-78.

[7] H.X. Wu, S.K. Cheng and S.M. Cui: IEEE Transactions on Magnetics, Vol. 41 (2005) No. 1, pp. 509-513. 